\title{
Sulfur- and metal content, isotopic S and C- geochemical signs of oil genesis
}

\begin{abstract}
Currently, a number of evidences witness the significant role of endogenic factors in oil and gas formation. It has been suggested that the components of endogenic fluids participate in the generation of oil systems. It is a common opinion that the most probable route of the formation of oils abiogenic part involves the reactions of oxides with hydrogen (Fischer-Tropsch synthesis).

This point of view as well as the notions on the origin of oil from bio-systems does not give clear understanding of the sources of oil heterocomponents, including, first of all, S, vanadium (V) and nickel (Ni). Stable correlations between concentrations of these components and other characteristics of oils allow one to conclude that sulfur and metals (which are contained in endogenic fluids) may play a certain role in oil formation.

In the present work we report that the interaction of endogenic $\mathrm{CH}_{4}$ and sulfur, owing to the ability of the latter to initiate condensation transformations of hydrocarbons, can lead to the generation of oil different type of hydrocarbons, sulfur-organic compounds and higher molecular structures such as asphaltenes and resins. In the course of these transformations, the metals aforementioned exert (due to their catalytic properties) various effects on hydrocarbon structures.
\end{abstract}

The data presented in the paper make it possible to explain some regularities of oil composition, which are poorly understandable from the positions of conventional views on oil genesis. Such regularities are as follows:

i. Stable correlations between concentration of sulfur, metals and density and viscosity of oils, ratio of oil fractions as well as scales of oils deposits.

ii. Vertical zoning of distribution of different composition oils.

iii. Dependence of oil composition on the prevalence of such metals as V and Ni in oils.

Isotopic transformation of carbon and sulfur, oils fraction, individual hydrocarbons and other natural systems are also discussed.
Volume 2 Issue 2 - 2017

\section{MA Lurie, FK Schmidt}

The Institute of oil- and carbochemical synthesis, Irkutsk State University, Russia

Correspondence: MA Lurie, The Institute of oil-and carbochemical synthesis, Irkutsk State University, Russia, Email miklur@rambler.ru

Received: December 23, 2016| Published: February 28, 2017

\section{Introduction}

Over the last decades, many evidences have been found to support the theory of organic origin of oil and gas. At the same time, a number of facts indicating the effects of endogenic factors on oil genesis are growing. The oil origin should be considered as a result of interaction of two different flows of matter and energy. The sources of oil components should include not only organic matter $(\mathrm{OM})$, mineral skeleton of natural reservoir and stratal waters, but also deep endogenic fluids. ${ }^{1}$ Independently on the available opinions about oil origin, the researchers should explain the reasons causing the association of elements observed in oils. Are heteroelements, in particular S and metals, the "satellites" constituting the hydrocarbons system and imparting some specific properties to oil? Or these elements due to their reactivity play more significant role even on early stages of oil formation, thus determining its geochemical type? The latter assumption is supported by numerous evidences on stable direct correlations between concentrations of $\mathrm{S}, \mathrm{V}+\mathrm{Ni}, \mathrm{V}$, ratio $\mathrm{V} /$ $\mathrm{Ni}$, concentration of aromatic compounds, asphalt-resin components, values of viscosity and density. ${ }^{2}$ Within the framework of organic theory of oil origin it is difficult to find an approach to explain stability of these correlations, especially when these characteristics are widely ranged.
The assumption of endogenic contribution to oil genesis prompts us to answer the question concerning the sources of carbon and heteroelements of abiogenic constituent of oil. Carbon could be found in endogenic fluids as carbon monoxide $(\mathrm{CO})$, carbon dioxide $\left(\mathrm{CO}_{2}\right)$ and methane $\left(\mathrm{CH}_{4}\right)$. The widespread viewpoint about genesis of abiogenic oil suggests the possibility of hydrocarbons formation in the course of hydrogenation of carbon oxides by hydrogen, which is contained in deep fluids (Fischer-Tropsch synthesis). However, the proceeding of these reactions in earth crust is hindered by many reasons. The presence of hydrogen sulfide $\left(\mathrm{H}_{2} \mathrm{~S}\right)$ and elemental sulfur $\left(\mathrm{S}^{0}\right)$ in some endogenic gas mixtures ${ }^{3,4}$ inhibiting the FischerTropsch reactions ${ }^{5}$ is the principal obstacle for realization of these processes. Besides, like in the case of organic theory of oil origin, substantial difficulties are connected with understanding the reasons of hereocomponents (which concentrations are changed according to the stable regularities mentioned) appearance in oil.

On the basis of the existing notions on composition of endogenic fluids, containing along with hydrogen $\left(\mathrm{H}_{2}\right), \mathrm{CO}$ and $\mathrm{CO}_{2}$ a number of other components possessing reactivity, in particular, $\mathrm{S}^{0}$, we have put forward the hypothesis ${ }^{6}$ that the starting reaction of the formation 
of oil abiogenic constituent involves the interaction of $\mathrm{CH}_{4}$ and its nearest homologs with $\mathrm{S}^{0}$. It is known ${ }^{7,8}$ that $\mathrm{S}^{0}$ initiates condensation reactions of $\mathrm{CH}_{4}$ and other hydrocarbons (HC) to furnish all types of oil S-organic compounds and hydrocarbons up to asphalt components. The increase of viscosity, density and content of heavy oil fractions with the grow of sulfur concentration as well as the increase of relative amount of S-organic compounds in the series mercaptanes $\rightarrow$ sulfides $\rightarrow$ thiophenes is in a good agreement with the regularities of the system HC-S ${ }^{0}$ evolution. ${ }^{6}$ It has also been suggested that the role of sulfur in the formation of oil components and sulfide ores makes these processes to some degree interconnected. This assumption is confirmed by the fact of joint deposits of metal sulfides and oil hydrocarbons.

Sulfides of different metals (Fe, $\mathrm{Ni}$, etc) are also capable of formation of higher molecular hydrocarbons from $\mathrm{CH}_{4}$. Ethylene and propylene are generated without addition of elemental sulfur. ${ }^{9}$ Obviously, this fact is caused by higher mobility of sulfur in metal sulfides. In geochemical systems, the fugitivity of sulfur is very high. ${ }^{10}$ As a rule, the real surface of metal sulfides is depleted with metals. In this metal-deficient layer, sulfur can be presented in mono-,di- and polysulfide forms, i.e. in the state close to elemental. ${ }^{11,12}$ That is why metal sulfides are likely to be catalysts of hydrocarbons condensation.

Additionally, it is known that the contact of butane, butylene and other light $\mathrm{HC}$ with metal sulfides gives S-organic compounds contained in oils. Such reactions proceed through the interaction of $\mathrm{HC}$ with surface sulfur. The reactions rate increases with enhance of surface sulfur mobility. ${ }^{13}$ Thus, metal sulfides promote the formation of carbohydrate system containing sulfur.

The hypothesis proposed by the authors could help to investigate the correlations of sulfur concentration in oil with such characteristics of oil deposits as size, vertical zoning of different oils distribution as well as the dependence of oil properties on the prevalence of one or other metal $(\mathrm{V}, \mathrm{Ni})$.

\section{The correlation of sulfur content in oil with the scale of its accumulation}

It is obvious that the higher content of $\mathrm{S}^{0}$ in deep fluid the higher scales of condensation transformations of hydrocarbon gas to deliver more sulfur-bearing hydrocarbon system. Correspondingly, the contribution of a gas to oil and gas system will be lower. Indeed, such a regularity has been found ${ }^{14}$ both for some countries and continents Figure 1 and for a specific region (Western Siberia). Another evidence in favor of the hypothesis on the effects of sulfur concentrations on deposits and qualitative composition of naphthides is the existence of highly sulfuric oils and bitumen which deposits are 3-4 times bigger than other ones. ${ }^{15,16}$ This observed regularity is hardly correlated with the organic theory. According to the latter, sulfurization is, first of all, a consequence of a secondary process (sulfate-reduction). To follow this logic, one should expect that in the case of strong accumulation of sediments and increase of $\mathrm{OM}$, the latter would be isolated from sulfate-containing waters, which access to OM might be hindered or even stopped. Therefore, an adverse regularity (as compared to those observed on Figure 1) would take place. Besides, one should bear in mind that the appearance of $\mathrm{S}$ in hydrosphere (in the form of easily soluble sulfates or sulfuric acid) occurs due to oxidative transformation of sulfides of rocks, i.e. it is more late process relative to the interactions of endogenic sulfur with ore and hydrocarbon components of the deep fluids. Sulfur, contained in the bio-systems, in the case of oil formation from only this source, could not provide the observed level of sulfur content in the majority of oils. Probably, it is just deep fluid that acts as a source of significant part of sulfur in oils. It is likely that low sulfur content can be attributed to the increased contribution of biogenic component to oil system.

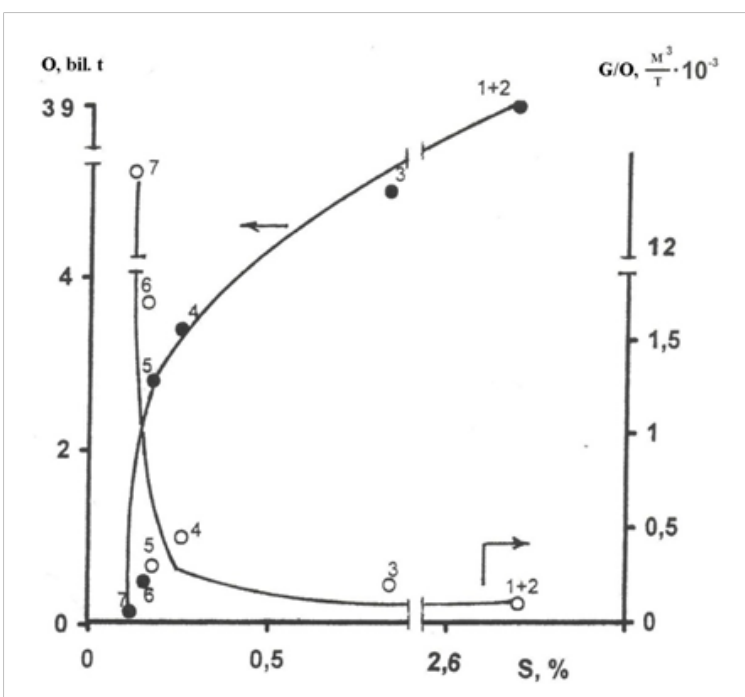

Figure I The influence of $S$ concentration in oils on their resources $(O)$ and the ratio of oils and gas resources (G/O). I -Saudi Arabia, 2 -Kuwait, 3 -Libya, 4 -Nigeria, 5- Indonesia, 6 -Australia, 7 -New Zealand.

The decrease of a part of gaseous component in oil and gas system Figure 1 caused by the increase of condensation effect of sulfur, should manifest itself in the characteristics of gases dissolved in oils. Indeed, statistical study of the data related to all oils of Russia have revealed $^{14,15}$ that gas factor of some oils as well as the $\mathrm{G} / \mathrm{O}$ value Figure 1 decreases with the growth of sulfur concentration Figure 2.

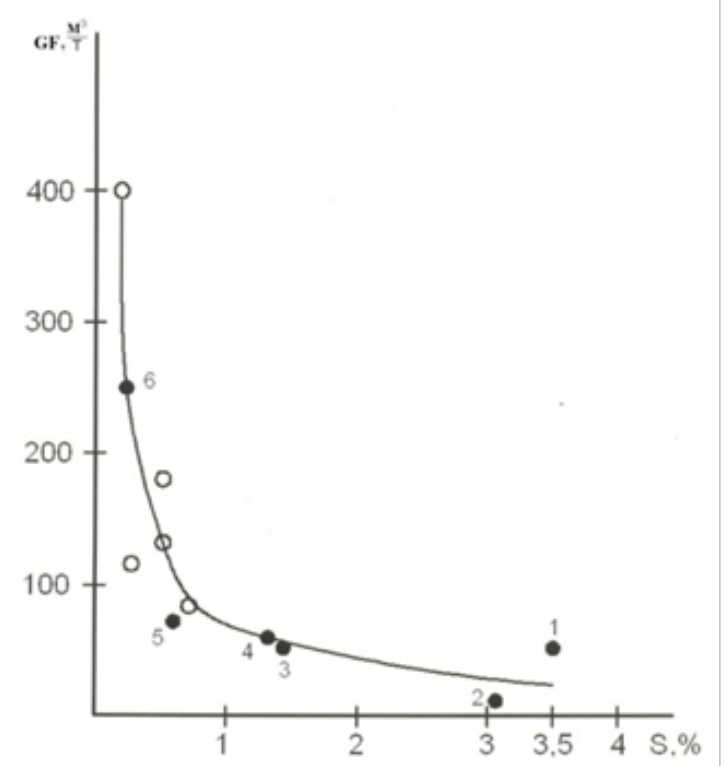

Figure 2 The Dependence of gas factor (GF) of oils on the content of S. O-oils of Bazhenov's set of Salym field. I-Romashkinskoye, 2-Arlanskoye, 3 Tuimazinskoye, 4 -Mukhanovskoye, 5-Samotlorskoye, 6 -Zhirnovskoye (fields).

It has been suggested ${ }^{6}$ that the formation of centers (poles) of oil accumulation and transport of oil towards the surface of the Earth that 
is in a good accordance with the observed concentric zoning of the indices of oils composition of the basic complexes of Western Siberia. ${ }^{14}$ Two groups of indices are changed in different directions from a center to periphery. The content of sulfur and asphalt components, oil density, $\mathrm{S} / \mathrm{N}$ ratio, content of $\mathrm{CH}_{4}$ relative to its homologs, total amount of trace elements, $\mathrm{V}$ content and $\mathrm{VO} / \mathrm{Ni}$-porphyrins ratio are reduced. At the same time, gas saturation and ratios of pristan / phytane, m-/o-xylene, $\Sigma$ xylol/ethylbenzene, six- and five-membered napthenes, as well as the content of such metals as $\mathrm{Ni}, \mathrm{F}, \mathrm{Mn}, \mathrm{Cu}$ and $\mathrm{Cr}$ are increased. It is likely that the regularity observed is conditioned by the increase of biogenic component from center to periphery.

\section{Vertical zoning of bedding of the different composition oils}

The methods of statistical and cluster analysis were used for the great number of oil basins. ${ }^{17}$ The results clearly show that low-sulfur and low-rubber oils are located in large depths. It has also been found that the closer to the surface of the Earth the higher concentration of S, aromatic, high-molecular compounds and asphalt elements. This regularity has not found any explanations from the viewpoint of traditional concepts. However, it can be rationalized from the position of the hypothesis proposed by the authors as follows. The ratio $\mathrm{H}_{2} \mathrm{~S}$ and $\mathrm{S}^{0}$, which are contained in the deep fluid, should be changed as the fluid becomes closer to the surface of the Earth and oxidative processes are intensified. The content of $\mathrm{S}^{0}$ must be increased due to oxidation of $\mathrm{H}_{2} \mathrm{~S}$. The latter does not practically show any ability to enlarge hydrocarbon structures. ${ }^{7,8}$ Thus, the condensation processes leading to the formation of higher-molecular components should be strengthened as the fluid becomes closer to the surface of the Earth.

These ideas are confirmed by the fact that $\mathrm{H}_{2} \mathrm{~S}$ has been found in light, deeply located oils having low content of S-organic compounds. ${ }^{18}$ In heavy oils, $\mathrm{H}_{2} \mathrm{~S}$ is absent. ${ }^{19}$ High concentration of $\mathrm{H}_{2} \mathrm{~S}$ is also observed in gas deposits and gas condensates in large depths. So, for example, its content in Astrakhan gas condensate (3-4 $\mathrm{km}$ depth) exceeds $24-25 \% .{ }^{1,20}$ The possible explanation of vertical spatial alteration of oil composition from the viewpoint of the theory of organic origin due to the destruction of oil structures contradicts to the data ${ }^{21}$ on the increase of content of less stable sulfur-containing components with growth of depth

\section{The effect of relative content of $\mathrm{V}$ and $\mathrm{Ni}$ in oils on their characteristics}

The presence of $\mathrm{V}$ and $\mathrm{Ni}$, possessing reactivity and first of all catalytic properties, in the deep fluids ${ }^{22,23}$ can effect dramatically on the evolution of hydrocarbon fluid. This fact also relates to the introduction of metals (in the form of different compounds) into oil. The differences in the character of catalytic action of $\mathrm{V}$ and $\mathrm{Ni}$ and quantitative ratio of these metals in various fluid systems should impart the definite specificity to oils. The available data confirm this assumption. "Nickel" oils $(\mathrm{Ni}>\mathrm{V})$ are light, they are located in large depths, contains $\mathrm{H}_{2} \mathrm{~S}$ and have low concentration of organosulfur compounds, rubbers and asphaltenes. "Vanadium" oils $(\mathrm{V}>\mathrm{Ni})$ are deposited in small or medium depths (1-3 km), they are heavy and have high content of sulfur and rubbers. ${ }^{24,25}$ The regularities observed correspond to the character of expected impact of these metals. Ni and $\mathrm{V}$ are clear antagonists with respect to hydrocarbon systems. Nickel belongs to hydrogenating agents and, therefore, can reduce $\mathrm{S}^{0}$ to $\mathrm{H}_{2} \mathrm{~S}$. Being active component of the catalysts of oil hydrodesulfurization, nickel facilitates the C-S bond cleavage in organosulfur compounds to afford $\mathrm{H}_{2} \mathrm{~S}$. Therefore, the predominance of Ni leads to weakening the condensation effect of S-containing component of the fluids. As a result, the condensation degree of oil and its sulfur content decreases. Contrary to this, $\mathrm{V}$ and its compounds, being catalysts of oxidation, in the presence of such oxidant as $\mathrm{S}^{0}$ should enhance the processes of oxidative dehydrocondensation of hydrocarbons. Of special importance is the ability of vanadium sulfide to oxidize $\mathrm{H}_{2} \mathrm{~S}$ to $\mathrm{S}^{026}$ that, in its turn, enhances the condensation ability of S-containing component of the fluids and promotes to weighting of oil and growth of sulfur content in oils.

Para genesis of $\mathrm{V}+\mathrm{S}$ with their increased concentrations is a characteristic feature of many hydrocarbon systems (heavy sulfur oils, bitumens, asphaltites, shales). In hard bitumens, the $\mathrm{V}$ content reaches 4.5 , and in heavy sulfuric oils $-6 \mathrm{~kg} / \mathrm{t}^{16,27}$ In deposits of asphaltites connected with sulfuric oil, the concentration of $\mathrm{V}$ is up to $6 \%$ with the formation of $\mathrm{VS}_{2} \cdot{ }^{28}$

The comparison of properties of "vanadium" oils and shales represents a special interest for the study of $\mathrm{V}$ and $\mathrm{S}$ para genesis reasons. Geochemically, they correspond to each other with respect to $\mathrm{V}$ content (some $\mathrm{kg}$ per ton), conditions of depositing and carbon isotopes. This fact points to the connection of $\mathrm{V}$ concentrations with hydrocarbon generation in magmatic centers and is indicative of similar mechanisms of black shales formation with genesis of "vanadium' oils. ${ }^{16}$ It is impossible to imagine that $\mathrm{V}$ and $\mathrm{S}$ could be obtained in such amounts from organic matter. This confirms the assumption that they are introduced by hydrocarbon fluids from the depths. Since the shales formation is accompanied by wide intake of $\mathrm{H}_{2} \mathrm{~S}$ from the depth, ${ }^{16}$ one can suppose that it is just the ability of vanadium sulfide to generate $S^{0}{ }^{26}$ that intensifies the condensation processes of hydrocarbon systems.

The fact that "vanadium" oils are located closer to the surface of the Earth as compared to "nickel" oils is probably connected with high migration activity of $\mathrm{V}$, joint movement of $\mathrm{V}$ and $\mathrm{HC}$ in the fluid flow, high affinity of vanadium to $\mathrm{HC}$ and its concentration in the course of hydrocarbons evolution. The content of $\mathrm{V}$ in oil shale is two times higher than in sediments, and the generation of its sulfide deposit is possible only in the case of extremely high-sulfur oils. ${ }^{16}$ In the US, $2 / 3$ of vanadium is extracted from oil. ${ }^{28}$ Unlike this, nickel sulfide is crystallized in rocks as huge massifs.

In the course of the fluid movement towards the surface of the Earth and intensification of oxidizing conditions, the content of the oxidized form $\left(\mathrm{V}^{5+}\right)$, which shows migration activity, ${ }^{29}$ can increase. The investigations of rock cores of Western Siberian oil beddings using a method of secondary ionic mass spectrometry ${ }^{30}$ has shown that intensity of $\mathrm{V}$ peaks increases with decrease of deposits depth. As far as $\mathrm{Ni}$ is concerned, such regularity is not observed.

\section{Isotopy of oils carbon}

To prove the possibility of oil abiogenic synthesis in depths of the Earth one should use isotope ratios of carbon in various hydrocarbon systems. It is known that general trend of carbon oxidation is accompanied by the following scheme of ${ }^{13} \mathrm{C}$ isotope enrichment: $\mathrm{CH}_{4} \rightarrow \mathrm{C} \rightarrow \mathrm{CO}_{1-3} \rightarrow \mathrm{CO}_{2} \rightarrow \mathrm{CO}_{3}{ }^{-2}$. ${ }^{31}$ The concentration of heavy isotope $\left(\delta^{13} \mathrm{C}\right)$ for $\mathrm{CH}_{4}$ (biogenic and geothermal) is from -30 to $-70, \mathrm{CO}_{2}$ atmospheric -7 , and marble $-3.0 \%$ (Faure, 1986). From the regularity of carbon isotope composition alteration in the course oxidability (reducibility) changing follows that in the case of multicomponent carbon-containing systems, where quantitative ratio of components 
with various degree of oxidability (reducibility) varies, the range of $\delta^{13} \mathrm{C}$ changing can reach high values. So, for proteins, carbohydrates, cellulose, lignin and lipids ${ }^{31}$ these values are $-17 \ldots-28 \%$, while for plants, $\mathrm{OM}$ of modern sediments and oil they equal $-6 \ldots-34,-10 \ldots-32,-$ 18...-34, respectively (Faure, 1986). In kerogen of metamorphized rocks, due to the effect of oxidation, reduction, etc. the spread in $\delta^{13} \mathrm{C}$ values is from -33 to -13 ; in various components of $\mathrm{OM}$-from -36 to -16.5 ; in bitumens - from -36 to $-15.5 \% .^{32}$ Therefore, the "direct" application of characteristics of carbon isotope composition of complex hydrocarbon systems for the research of oil genesis is not quite fruitful. More reasonable is the usage of isotope ratios for narrower fractions of hydrocarbon systems and individual HC.

According to the work, ${ }^{33} \delta^{13} \mathrm{C}$ value for $\mathrm{CH}_{4}$ of different fields is $-36 \ldots-46 \%$. For liquid alkanes of oil these values are changed to $-31 \ldots-$ $38 \%$, and for aromatic fraction - to- $27 \ldots-30 \%$. ${ }^{34}$ The enrichment with ${ }^{13} \mathrm{C}$ isotope is observed as follows ${ }^{35} \mathrm{CH}_{4}(-38 \ldots-46)<$ liquid $\mathrm{HC}$ of oil $(-27 \ldots-38)<$ oil bitumens, asphaltites $(-18 \ldots-24)<$ mantle $\mathrm{CO}_{2}(-7.2)$ $<$ heavy diamonds $(-2.0 \ldots-7.2 \%)$. As a whole, carbon in natural gas is depleted with ${ }^{13} \mathrm{C}$ more strongly than the associated oil. ${ }^{36} \mathrm{It}$ is known ${ }^{37}$ that asphaltenes of oils in comparison with other oil components have the heaviest carbon isotope composition. The growth of asphaltenes content in oils of Western Siberia leads to the increase of ${ }^{13} \mathrm{C}$ concentration in both asphaltenes and oils. ${ }^{14}$ The characteristics of bitumens inclusions to minerals, formed in hydrothermal processes, also confirm the growth of heavy carbon isotope composition during the increase of condensation degree..$^{38}$ For liquid oil-like bitumens, malthas, asphaltenes and kerites the values of $\delta^{13} \mathrm{C}$ are $-23 \ldots-33$; $-24 ;-23$; and $-19 \%$, respectively. Similar regularity is observed for individual $\mathrm{HC}$. The enrichment with heavy isotope occurs with the increase in molecular weight of gas systems $\mathrm{C}_{1}-\mathrm{C}_{4}{ }^{36} \mathrm{In}$ particular, in case of giant fields of China the value $\delta^{13} \mathrm{C}$ is -34 for $\mathrm{CH}_{4},-26$ for $\mathrm{C}_{2}$, -25 for $\mathrm{C}_{3}$ and $-23 \%$ for $\mathrm{C} 4$. In hydrothermal field of Juan-de-Fuca ridge, the $\delta^{13} \mathrm{C}$ value of $\mathrm{CH}_{4}$ is $-51 \ldots-54$, for $\mathrm{C}_{2-7}$ (basically, alkanes) the enrichment of ${ }^{13} \mathrm{C}$ reaches-20...-25, and for toluene-20\%o. ${ }^{25}$

Rudenko and Kulakova ${ }^{35}$ have proposed to consider the abiogenic polycondensation of $\mathrm{CH}_{4}$ as a model of isotope fractionating in a course of $\mathrm{HC}$ transformations. Catalytic polycondensation of $\mathrm{CH}_{4}$ induces the following enrichment of ${ }^{13} \mathrm{C}: \mathrm{CH}_{4} \rightarrow$ volatile products of polycondensation $\rightarrow$ nonvolatile products. ${ }^{39}$ The direction of isotopes ratio changing, observed for the components of real oils and naphthides (see above) is similar to those shown in the abovementioned model. Therefore, the conclusion that the carbon isotope composition in oil systems is determined by isotope fractionating in condensation abiogenic processes and testifies to their essential contribution to oil formation, is quite justified.

Following the logic of the concept of oil origin only from OM of sedimentary rocks, one should expect that oil would be enriched by heavy isotope in comparison with OM, since the bonds, formed by an easy isotope, are less strong, ${ }^{36}$ and the destructive transformations of $\mathrm{OM}$ to oil should involve a removal of the structures containing an easy isotope. However, it is difficult to find the expected enrichment (see above).

It has been reported ${ }^{31,35}$ that the isotope composition of deuterium in oils and $\mathrm{CH}_{4}$ of oil and gas deposits also speaks in favor of a deep origin of these hydrocarbon systems. It is necessary to remind that from 450 discovered oil fields only 54 are connected with sedimentary rocks,$^{40}$ while according to the data ${ }^{41}$ from 600 sedimentary reservoirs in the world only $1 / 3$ is oil-bearing.

\section{Isopoty of oil sulfur}

The result of comparison of $\mathrm{S}$ isotope composition of mantle origin, marine (oceanic), sediment, bio-systems as well as oil itself might be the major argument in favor of one or another opinion about $\mathrm{S}$ source in oils. The value $\delta^{34} \mathrm{~S}$ in oils changes from -8 to $+32 \%$, but for a significant number of fields (marine origin, cretaceous, tertiary and late triassic age, Western Siberia) this range is significantly less (from-7 to $+5 \%$ ). ${ }^{14,36}$ Various contribution of mantle, sulfate $\mathrm{S}$ and $\mathrm{S}$ of bio-systems can be one of the reasons of variations of $\delta^{34} \mathrm{~S}$ values.

Essential difference of isotope compositions of $\mathrm{S}$ in mantle from meteoric is improbable. In this connection, it is necessary to pay attention to close $\delta^{34} \mathrm{~S}$ values of brimstone $\mathrm{S}(+2.5 \ldots+4.0 \%)$ of salt domes containing oil (Mexico) and mantle S. ${ }^{36}$ Even in a case of only mantle origin of S oils, some changing of its isotope composition is possible due to the variation of isotope composition of mantle $\mathrm{S}$. The latter can depend in a certain degree on temperature, magma structure, $\mathrm{S}$ fugitivity. So, for sulphide magmatic minerals the $\delta^{34} \mathrm{~S}$ deviations are $-11 \ldots+9 \%{ }^{36}$

Considering the possibility of occurrence of sulphatic S in oil, one should bear in mind that $\mathrm{H}_{2} \mathrm{~S}$ evolved during the reduction possesses weaker ability (in comparison with $\mathrm{S}^{0}$ ) to "sulfurize" hydrocarbon structures. Besides, bacterial sulfate-reduction (at diagenesis stage, low temperatures) leads to strong depletion of the reduced forms of sulfur with heavy isotope. The values $\delta^{34} \mathrm{~S}$ of sulphate $\mathrm{S}$ in hydrosphere and sulphates of sedimentary rocks are $+20 \ldots+30 \%$. In $\mathrm{H}_{2} \mathrm{~S}$, the value $\delta^{34} \mathrm{~S}$ reaches $-11 \ldots-50 \%$, and in a sulphide phase in diagenesis zone this value is $-10 \ldots-40 \% 0^{36,42}$ that strongly differs from isotope composition of oil S. It is unlikely that "sulfurization" of hydrocarbon structures proceeds intensively during low-temperature sulfate-reduction. Under thermal sulfate-reduction the rate of this process can increase. At the same time the growth of temperature should lead to fading the effect of isotope fractioning. In some cases $\mathrm{S}$ in $\mathrm{H}_{2} \mathrm{~S}$ and initial sulphates under the conditions of high-temperature sulfate-reduction is not distinguishable on isotope composition, and the value $\delta^{34} \mathrm{~S}$ in $\mathrm{H}_{2} \mathrm{~S}$ gases of large hydrocarbon provinces is +10 $\ldots+15 \%{ }^{42}$ Therefore thermal sulfate-reduction can promote to enrichment of oil sulfur with heavy isotope. Certain enrichment can occur also because of the introduction of bio-structures in oil, where, as it is known ${ }^{36}$ the value $\delta^{34} \mathrm{~S}$ is $+15 \ldots+20 \%$. In this connection, the particular interest for revealing the sources of oil S represents isotope composition of oil S of Western Siberia, where the reservoir waters contain no sulfates, and the value $\delta^{34} \mathrm{~S}$ for these oils is $-7.4 \ldots+4.3$ $\%$. ${ }^{14}$ If to admit that the absence of sulfates is caused by their total reduction with "incorporation" of S into oil, one should expect high enrichment with heavy isotope (up to $+20 \ldots+30 \%$ ). One can conclude here that not sulfate-reduction, but $\mathrm{S}$ of bio-systems and mantle $\mathrm{S}$ should be the source of $\mathrm{S}$ in these oils. However bio systems, owing to low concentration of S, cannot provide the sulfur content observed in the majority of oils. ${ }^{43}$ The decrease of sulfur content and possibly connected with it the increase of the contribution of bio systems may lead to some enrichment of oil with S heavy isotope that is really observed for this region Figure 3 and for other oils and condensates. ${ }^{14}$

Thus, the interaction of endogenic $\mathrm{CH}_{4}$ (its closest homolgs) and $\mathrm{S}^{0}$ followed by the condensation processes and the formation of oil components does not contradict a complex of the data on characteristics of real oil systems. The data on isotope composition of $\mathrm{C}$ and $\mathrm{S}$ of oils are in agreement with regularities of isotope fractioning of $\mathrm{C}$ and $\mathrm{S}$, occurring during the evolution of natural systems. ${ }^{44}$ 


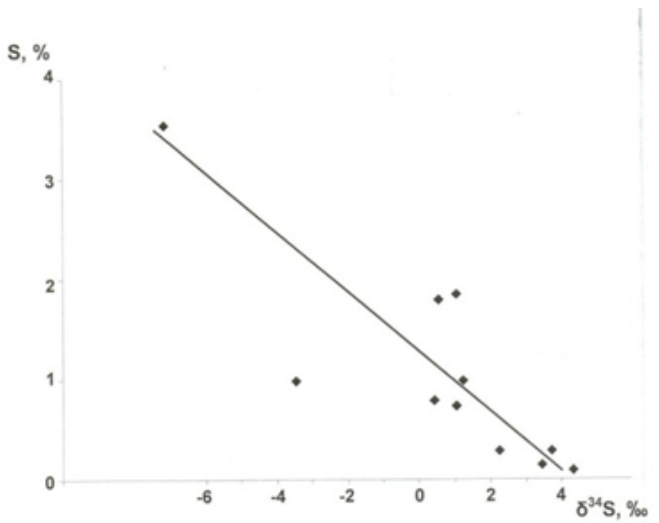

Figure 3 The dependence of $\delta^{34} S$ on $S$ concentration in oils of Western Siberia.

\section{Conclusion}

The data on composition of endogenic gas fluids and reactivity of their components $\left(\mathrm{CH}_{4}, \mathrm{H}_{2} \mathrm{~S}, \mathrm{~S}^{0}\right.$, metals, etc.) allows one to rationalize the possibility of realization of one of the routes to the formation of abiogenic part of oil as well as to explain the regularities in variations of real oil systems indices.

Elemental sulfur is able to initiate the oxidative dehydrocondensation transformations of hydrocarbons including methane and its close homologs. The influence of $\mathrm{S}^{0}$ on $\mathrm{CH}_{4}$ can lead to the generation of all types of $\mathrm{HC}$ and S-organic components of oils. The higher concentration of sulfur in the fluid the more intensive the processes of formation of oil components and the more sulfur system will be reached. At the same time, the part of non-condensed gas in the system should decrease. The available data on several oil fields support the point of view presented in the work.

The increase in sulfur content, viscosity and density of oil with the decrease of occurrence depth observed in the majority of oil fields can be explained by intensification of oxidative conditions and oxidation of $\mathrm{H}_{2} \mathrm{~S}$ to $\mathrm{S}^{0} . \mathrm{H}_{2} \mathrm{~S}$ is not able to initiate the condensation transformations of $\mathrm{HC}$, therefore the deeper-embedded hydrocarbon systems are less condensed and contain significant amounts of $\mathrm{H}_{2} \mathrm{~S}$ (light oils, gas condensates, gases).

Metals $\mathrm{V}$ and $\mathrm{Ni}$ due to the peculiarities of their catalytic properties should exert adverse action on the hydrocarbon systems. Vanadium, being the carrier of oxidative action, should strengthen oxidative dehydroconsensation transformations of $\mathrm{HC}$. Besides, vanadium sulfide occurring in hydrocarbon systems can oxidize $\mathrm{H}_{2} \mathrm{~S}$ to $\mathrm{S}^{0}$ and additionally enhance the condensation transformations. Contrary to this, $\mathrm{Ni}$ is hydrogenating agent and it is capable to increase $\mathrm{H}_{2} \mathrm{~S}$ content as well as to destroy the C-S bond to afford $\mathrm{H}_{2} \mathrm{~S}$. These features of $\mathrm{Ni}$ should promote to the formation of more light and less sulfur oils.

The compositions of real oils with predominance of $\mathrm{V}$ or Ni are in good agreement with the assumed character of influence of these metals on hydrocarbon systems. The data on isotope ratio of $\mathrm{C}$ and $\mathrm{S}$ in oils, their fractions, individual compounds do not contradict to the notions on participation of endogenic $\mathrm{CH}_{4}$ and $\mathrm{S}$ in the formation of abiogenic part of oil and gas systems.

\section{Acknowledgements}

None.

\section{Conflict of interest}

The author declares no conflict of interest.

\section{References}

1. Dmitrievsky AN. Vital Importance of Oil and Gas Extractive Industry. Vestnik Akad Nauk. 2008;78:704-711.

2. Eigenson AS. On confrontation of two concepts of oil and gas formation. Khimiya i Teknologiya Topliv I Masel. 1998;3:3-5.

3. Letnikov FA. Ultradeep fluid systems of the earth and problems of ore formation. Geologiya Rudnykh Mestorozhdenii. 2001;43:291-307.

4. Malyshev AI. Peculiarities of sulfur's behavior in the magmatic process. Dokl Akad Nauk. 2000;374:675-677.

5. Anderson RB. The Fischer-Tropsch Synthesis. New York: Academic Press; 1984. $293 \mathrm{p}$

6. Lure MA, Shmidt FK. Condensation transformations of endogenic methane under the influence of sulfur - possible route of oil genesis. Russ Khim Zh. 2004; 6:135-147.

7. Voronkov MG, AN Pereferkovich, MP Gavar, et al. Reactions of Sulfur with Organic Compounds. Chemistry of Heterocyclic Compounds. 1979;6(9):1103-1105.

8. Savchenko VI, Didenko LP, Zav yalova LV. Interaction between methane and sulfur with the formation products of partial oxidation and condensation of methane. Kinetica I Kataliz. 1996;37:165-170.

9. Kutsch SD, Savchenko VI. Dehydrodimerization of methane on metal sulfides. Bulletin of the Academy of Sciences of the USSR. Division of chemical science. 1989;38(4):883-883.

10. Korzhinsky DS. Theoretical Foundations of Minerals Paragenesis. Nauka, Moscow; 1973. 288 p.

11. Mikhlin Yu L. Non-equilibrium non-stoichiometric layer in the reactions of metal sulfides. Glass Physics and Chemistry. 2001;33(4):402-410.

12. Tauson VL, Babkin DN, Lustenberg EE, et al. Surface typochemistry of hydrothermal pyrite:electron microscopic and scanning probe microscopic data. 1. Synthetic pyrite. Geochemistry International. 2008;46(6):565-577.

13. Mashkina AV. Catalytic reactions of dialkyl disulfides. Kinetics and Catalysis. 2008;49(6):802-811.

14. Goncharov IV. Geochemistry of Oils of Western Siberia. Nedra, Moscow, 1987. $181 \mathrm{p}$.

15. Glagoleva OF. Technology of Petroleum Processing. Part 1. Primary Petroleum Processing. Khimiya. 2006. 399 p.

16. Marakushev AA, Marakushev SA. The Nature of oil geochemical specificity. Dokl Akad Nauk. 2006;411:111-117.

17. Polyschuk Yu M, Yaschenko IG. Regional diversity of chemical composition of Eurasian oils. Geologiya Nefti i Gaza. 2001;5:40-44.

18. Siraeva IN, Ulendeeva AD, Parfenova MA. Organosulfur compounds of oils of different types. Nefteperarabotka i Neftekhimiya. 2002;9:33-39.

19. Eigenson AS, Sheikh Ali DM. Regularities of component and fraction and chemical compositions of oils. Khimiya $i$ Teknologiya Topliv I Masel. 1988; 10:29-34.

20. Eremenko NA, Chilingar GV. Geology of Oil and Gas on the Boundary of Centuries. Nauka, 1996. 176 p.

21. Gerasimova NN, Nikolaeva TN, Kovalenko E Yu. Distribution of nitrogen- and sulfur-organic compounds in oils of Jurassic and Paleozoic complexes of Western Siberia. Neftekhimiya. 2003;43:266-272. 
22. Letnikov FA. Fluid mechanism of destruction of continental earth's crust and formation of sedimentary oil-gas-bearing basin. Dokl Akad Nauk. 2005;401:205-207.

23. Slobodsky RM. Elementoorganic Compounds in Magmatogenic and Ore-Forming Processes. Nauka, Novosibirsk; 1981. 133 p.

24. Nukenov DN, Punanova SA. In: Modern Problems of Geology of Oil and Gas. Nauchny Mir. Moscow; 2001. p. 357-353.

25. Marakushev AA, Marakushev SA. Hydrocarbons redox facies and oil origin. Dokl Akad Nauk. 2007;414:83-89.

26. Janssens JP, van Langeveld AD, Moulijn JA. Characterization of alumina- and silica-support vanadium sulphide catalysts and their performance in hydrotreating reactions. Applied Catalysis A: General. 1999;79(1-2):229-239.

27. Beskrovny NS. Naphthometallogeny:unity of oil and ore formation. $Z h$ Vsesoyuzn Khim Obtsch. 1986;31:569-574.

28. Avdonin VV, Boitsov VE, Grigorev VM. Deposits of Metal Minerals. Tripsta, Moscow; 2005. 717 p.

29. Kuspanova BK, Nasyrov AR, Ishmukhanbetova NK, et al. Application of ESR method for determination of general vanadium in oils and their ashes. In: Proceeding of the $4^{\text {th }}$ Intern. Conf. "Oil and Gas Chemistry". Tomsk, 2000;1:121-123.

30. Bilotas OP, Tsyro LV, Unger FG. Study of cores using secondary ionic mass-Spectrometry. In:Proceeding of the $4^{\text {th }}$ Intern. Conf. "Oil and Gas Chemistry". Tomsk, Russia, 2000. 1:101-103.

31. Pirogov S Yu, Akulov LA, Vedernikov MV. Natural Gas. Methane. Professional. St Petersburg, 2006. 847p.

32. Syngaevskii ED, Shchegolkov YV, Vitozhents G, et al. Isotopicgeochemical signs of coal and bitumen transformations in different-type ore mineralization. 2007;42(6):572-583.

33. Kuklinsly A Ya. Isotopic carbon composition of methane of oil, gas condensate and gas fields. In: Proceeding IX Symp. On Stable Isotopes in Geochemistry. Moscow; 1982;1:256-257
34. Bogacheva MP, Kodina LA. Intramolecular isotopic effects in biological compounds and product of their geochemical transformations. In: Degassing of Earth and Geotectonics. Nauka, Moscow; 1985. p. 66-69.

35. Rudenko AP, Kulakova II. Deep synthesis of oil and gas hydrocarbons in open catalytic systems and possibility of existence of fields with selfrenewable resources. In: Genesis of Hydrocarbon Fluids and Fields. 2006;68-83.

36. Faure G. Principles of Isotope Geology. Singapore: John Willy and sons; 1986. $590 \mathrm{p}$.

37. Galimov EM. Investigations of Organic Matter and Gases in Sedimentary Rocks of World Ocean Bottom. Nauka, Moscow; 1973. 284 p.

38. Shumyansky VA, Lensky SD. Isotopic composition of carbon of hydrothermal bitumens depending on temperature of their formation. In:Proceeding IX Symp. On Stable Isotopes in Geochemistry. 1982;1:6264.

39. Bobrov VA, Digonsky SV, Krivomazova IG. Origin of fossil carbon compounds. In:Degassing of Earth and Geotectonics. Nauka, Moscow, 1985. p. 88-89.

40. Krayushkin VA. About theory of deep abiotic origin of oil and natural gas. In: Forecast of Dimondiferous of Fundament of Old and New Platforms, Izdatel'stvo Kazanskogo Universiteta. Kazan, Russia, 2001. p.120-123.

41. Trofimov VA, Korchagin VI. Evaluation of ideas about oil fields formation (from position of their deep origin). Geologiya Nefti i Gaza. 2005. 2:51-54.

42. Vinogradov VI. Was there a conflict at the Neoproterozoic-Cambrian boundary:evidence from sulfur isotope composition. Lithology and Mineral Resources. 2007;42(1):1-14.

43. Dai J, Li J, Ding W, et al. Geochemical characteristics of natural gas at giant accumulation in China. Journal of Petroleum Geology. 2007;30(3):275-288.

44. Savchenko VI, Didenko LP, Sementsova LA. Thermodynamic possibility of condensation products formation by the interaction of methane with hydrogen sulfide. Neftekhimiya. 1998;38:68-74. 